\title{
Evaluation of Serum Magnesium Level in Pregnant Women with and without Gestational Diabetes Mellitus
}

\author{
Namitha Vijay \\ Department of Biochemistry, Adichunchanagiri Institute of Medical Sciences, India
}

Copyright $\subseteq 2018$ by authors, all rights reserved. Authors agree that this article remains permanently open access under the terms of the Creative Commons Attribution License 4.0 International License

\begin{abstract}
Gestational diabetes mellitus (GDM), a glucose intolerance state during pregnancy is a strong predictor of post-partum prediabetes and one of the risk factors for overt type 2 diabetes $\left(T_{2} D M\right)$. Magnesium a trace element influences the cell's response to insulin and decreased levels of magnesium are related to insulin resistance and $T_{2} D M$. Several literatures are available on effects of magnesium on $\mathrm{T}_{2} \mathrm{DM}$ with dearth in research regarding the impact of magnesium on GDM. In this backdrop our present study was designed to determine serum magnesium level in women with and without GDM. A cross sectional case control study was conducted at Adichunchanagiri Institute of Medical Sciences and Hospital. The total numbers of subjects were 90, divided into two groups, Group I- 45 pregnant women with Gestational diabetes mellitus as cases, Group II- 45 pregnant women without GDM as controls. Blood samples were drawn under aseptic precautions from study subjects. Serum magnesium levels were determined by commercially available Calmagite kit method. The mean serum magnesium level was found to be significantly lower in group I subjects when compared to group II subjects with the $p$ value $<0.0001$. To conclude, results of our study demonstrated that hypomagnesaemia an underlying factor in determining disrupted glucose metabolism in pregnant women and magnesium supplementation might help patients with GDM to control their metabolic profile and pregnancy outcomes.
\end{abstract}

Keywords Pregnant Women, Gestational Diabetes, Hypomagnesaemia, Glucose Tolerance

\section{Introduction}

Gestational diabetes mellitus (GDM), defined as glucose intolerance during pregnancy and is a strong predictor of postpartum prediabetes and transition to overt type 2 diabetes $\left(\mathrm{T}_{2} \mathrm{DM}\right)^{[1]}$. Approximately $14 \%$ of all pregnancies are complicated by $\mathrm{GDM}^{[2]}$.

GDM is similar to $\mathrm{T}_{2} \mathrm{DM}$ in terms of pathophysiology in that insulin resistance is a cardinal factor ${ }^{[1]}$. It is associated with increased subsequent risk of developing diabetes, metabolic syndrome, cardiovascular events and the children of women with GDM have higher risks of developing obesity, prediabetes, and $\mathrm{T}_{2} \mathrm{DM}^{[3]}$. The Diabetes Prevention Program study results showed that women with GDM and impaired glucose tolerance (IGT) had a $74 \%$ increased risk of developing $\mathrm{T}_{2} \mathrm{DM}$ compared to women with no GDM history and normal glucose tolerance ${ }^{[4]}$. Until recently, obesity, sedentary life style and genetics were known risk factors for the development of type 2 diabetes. However, recent reports have revealed that there are many other possible risk factors, such as magnesium deficiency ${ }^{[1]}$.

Magnesium is a mineral that influences the cell's response to insulin and is involved in initiating the reaction that allows glucose to enter the cell ${ }^{[1]}$. It is also a cofactor for enzymatic reactions involved in carbohydrate metabolism. Decreased blood and tissue levels of magnesium are related to insulin resistance, $\mathrm{T}_{2} \mathrm{DM}^{[5-7]}$. Bardicef et $\mathrm{al}^{[8]}$ showed that intracellular magnesium depletion can occur especially in pregnant women affected by GDM.

Several literatures are available on effects of magnesium on $\mathrm{T}_{2} \mathrm{DM}$ with dearth in research regarding the impact of magnesium on $\mathrm{GDM}^{[9-11]}$. In this backdrop our present study was designed to determine serum magnesium level in pregnant women with and without GDM, which will help in better management and to prevent its further complications.

\section{Materials and Methods}

Pregnant women with gestational age between 24-28 weeks who came for regular checkup at Adichunchungiri Hospital and Research Centre, B G Nagar, Mandya were included in the study. A diagnosis of GDM was based on 
the American Diabetes Association Criteria ${ }^{[12]}$. Group 1(Case group) included cases of GDM diagnosed by a "one step" 2 -hour $75 \mathrm{~g}$ oral glucose tolerance test at 24-28 weeks of gestation. Women whose plasma glucose met one of the following criteria were diagnosed as GDM: Fasting $\geq 92 \mathrm{mg} / \mathrm{dl}, 1$ hour $\geq 180 \mathrm{mg} / \mathrm{dl}, 2$ hour $\geq 153 \mathrm{mg} / \mathrm{dl}$. Group 2(Control group) included pregnant women with normal Oral Glucose Tolerance Test (OGTT). Informed consent was taken and the study was approved by ethical committee of the institution. Patients with history of overt diabetes or type 1 diabetes, cardio vascular diseases (CVD), thyroid disorders, stage 2 hypertension (HTN), malignancy or severe renal or hepatic disease were excluded from the study. $4 \mathrm{ml}$ blood was drawn after a 12 hour overnight fast. $2 \mathrm{ml}$ in fluoride vaccutainer to measure plasma glucose by using glucose oxidase-peroxidase method and $2 \mathrm{ml}$ in plain vaccutainer to estimate magnesium levels by Calmagite method, both by using commercially available kit in Meril autoanalyser.

\section{Statistical Methods}

Descriptive and inferential statistical analysis had been carried out in the present study. Results were presented as Mean \pm SD (Min-Max) and $\mathrm{p}<0.05$ was considered statistically significant. Student $\mathrm{t}$ test (two tailed, independent) was used to find the significance of study parameters on continuous scale between two groups (Inter group analysis). Pearson linear correlation was used for evaluating the relationship between magnesium and 2-hr post $75 \mathrm{gm}$ oral GTT plasma glucose level.

\section{Results}

A total of 90 pregnant women were enrolled in the study of which 45 had GDM and 45 were normoglycemic by OGTT. The mean value of age of GDM and control groups were $24.71 \pm 4.47$ years and $23.64 \pm 2.94$ years while mean gestational age was $25.66 \pm 1.59$ weeks and $25.71 \pm 1.50$ weeks respectively and no statistical difference was observed. Pregnant women with GDM showed significant decrease in serum $\mathrm{Mg}^{2+}$ ( $\mathrm{p}$ value $<0.0001$ ) levels compared to pregnant women without GDM (Table 1 and figure 1). Serum $\mathrm{Mg}^{2+}$ showed a negative correlation with 2-hr post 75 gm oral GTT plasma glucose in both group 1 and group 2 subjects and it was statistically significant with $p$ value of 0.021 and 0.015 respectively (Table 2).

Table 1. Comparison of clinical and biochemical parameters of women with and without GDM (Mean \pm SD)

\begin{tabular}{|c|c|c|c|}
\hline & Group 1(n=45) & Group2(n=45) & P value \\
\hline Age(years) & $24.71 \pm 4.47$ & $23.64 \pm 2.94$ & 0.183 \\
\hline $\begin{array}{c}\text { Gestational age } \\
\text { (weeks) }\end{array}$ & $25.66 \pm 1.59$ & $25.71 \pm 1.50$ & 0.878 \\
\hline $\begin{array}{c}\text { 2-hr post 75g } \\
\text { OGTT plasma } \\
\text { glucose(mg/dl) }\end{array}$ & $160.66 \pm 13.68$ & $102.46 \pm 15.30$ & $<0.0001$ \\
\hline $\begin{array}{c}\text { Serum Mg } \\
\text { (mEq/L) }\end{array}$ & $1.55 \pm 0.43$ & $3.01 \pm 1.32$ & $<0.0001$ \\
\hline
\end{tabular}

OGTT - oral glucose tolerant test.

Table 2. Correlation of serum $\mathrm{Mg}^{2+}$ with 2-hr post $75 \mathrm{gm}$ oral GTT plasma glucose

\begin{tabular}{|c|c|c|}
\hline & r & p value \\
\hline Group 1 & -0.341 & 0.021 \\
\hline Group 2 & -0.359 & 0.015 \\
\hline
\end{tabular}

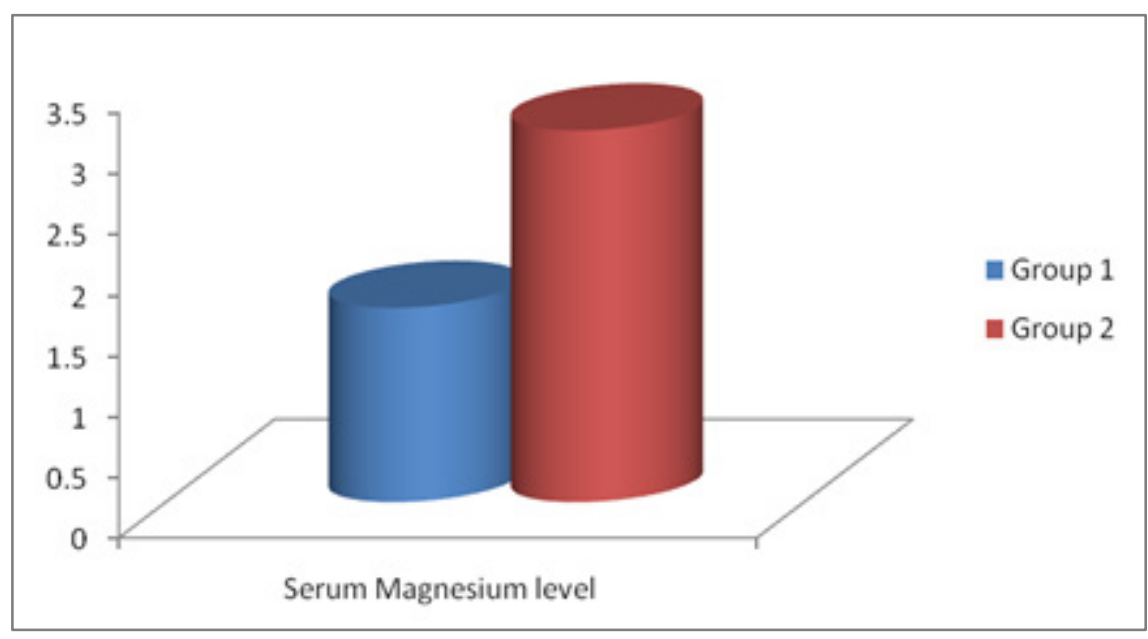

Figure 1. Serum Magnesium levels of women among two groups. 


\section{Discussion}

Diabetes mellitus is one of the most common diseases of the mankind that are associated with hypomagnesaemia[10,11]. GDM is a complex metabolic syndrome and one of the strongest predictors of prediabetes and type 2 diabetes mellitus[1]. Even though hypomagnesaemia is frequently observed in pregnant women, there are some discrepancy about magnesium depletion in women with GDM[1]. The aim of this study was to pursue possible relationships between serum concentration levels of magnesium and its role as a typical indicator in disrupted glucose homeostasis in gestational diabetic women, thus contributing to better understanding of the wide role of micronutrients in GDM complications.

In this study, serum magnesium level in women with GDM was less than that of control group (Table 1, $P<0.0001)$. This is in accordance with the study conducted by Mostafavi et al.,[13] they revealed that both serum and RBC magnesium levels were significantly lower in GDM patients than healthy pregnant women. The cause of hypomagnesaemia could be due to low dietary intake, increased nutritional needs, osmotic diuresis and by indirect hormonal effects[14].

Hyperglycemia is associated with oxidative stress and impaired trace element metabolism[15]. Furthermore, poor glycemic control is a well established risk factor for magnesium depletion. Studies have shown significant negative correlation between $\mathrm{Mg}^{2+}$ and fasting plasma glucose, $\mathrm{HbA}_{1} \mathrm{c}[11]$. Similarly, we found a significant negative correlation between serum $\mathrm{Mg}^{2+}$ level and 2-hr post $75 \mathrm{gm}$ oral GTT plasma glucose both in group $1(P<0.05)$ and $2(P<0.05)$ subjects(Table 2$)$, denoting declining of serum $\mathrm{Mg}^{2+}$ level as the level of blood glucose increase in pregnant women.

A study conducted by Asemi $\mathrm{Z}$ et al.,[16] showed that the administration of magnesium supplementation in women with GDM resulted in significant improvement in insulin resistance and thus effective maintenance glucose tolerance. Thus, early detection of hypomagnesaemia condition and replacement therapy of magnesium in pregnant women with GDM reduce the complications and it can be used as a one of the protective factors for pregnant women with GDM.

Our study had a few limitations. First, we could not follow up the GDM patients to check the pregnancy outcome. Second, intracellular magnesium is a better marker of magnesium status and we could not determine intracellular magnesium status. Large scale clinical trials are needed to evaluate whether correction of hypomagnesaemia condition could be beneficial to reduce the poor pregnancy outcome and further development of postpartum prediabetes and type 2 diabetes mellitus.

\section{Conclusions}

The mean serum magnesium level was found to be significantly lower in cases when compared to controls. To conclude, results of our study demonstrated that hypomagnesaemia an underlying factor in determining disrupted glucose metabolism in pregnant women and magnesium supplementation might help patients with GDM to control their metabolic profile and pregnancy outcomes.

\section{REFERENCES}

[1] Yang SJ, Hwang SY, Baik SH, Lee KW, Nam MS, Park YS et al. Serum magnesium level is associated with type 2 diabetes in women with a history of gestational diabetes mellitus:The Korea national diabetes program study. J Korean Med Sci 2014;29:84-9.

[2] Akhlaghi F, Bagheri MS, Rajabi O. A Comparative Study of Relationship between Micronutrients and Gestational Diabetes. ISRN Obstetrics and Gynecology2012; 2012:1-4.

[3] Brewster S, Zinman B, Retnakaran R, Floras JS. Cardiometabolic consequences of gestational dysglycemia. J Am Coll Cardiol 2013;62:677-84.

[4] Ratner RE, Christophil CA, Metzger BE, Dabelea D, Bennett PH, Pi-su-nyer $\mathrm{X}$ et al. Diabetes Prevention Program Research Group. Prevention of diabetes in women with a history of gestational diabetes:effects of metformin and lifestyle interventions. J Clin Endocriol Metab 2008;93:4774-9.

[5] Kim DJ, Xun P, Liu K, Loria C, Yokota K, Jacobs DR et al. Magnesium intake in relation to systemic inflammation, insulin resistance, and the incidence of diabetes. Diabetes Care 2010;33:2604-10.

[6] Song Y, Li TY, Van Dam RM, Manson JE, Hu FB. Magnesium intake and plasma concentration of markers of systemic inflammation and endothelial dysfunction in women. Am J Clin Nutr 2007;85:1068-74.

[7] He K, Liu K, Daviglus ML, Morris SJ, Loria CM, Van Horn $\mathrm{L}$ et al. Magnesium intake and incidence of metabolic syndrome among young adults. Circulation 2006; 113:1675-82.

[8] Bardicef M, Bardicef O, Sorokin Y, Altura BM, Altura BT, Resnick LM. Perinatal cellular ion metabolism:31P-nuclear magnetic resonance spectroscopic analysis of intacellular free magnesium and $\mathrm{pH}$ in maternal and cord blood erythrocytes. J Soc Gynecol Investig 1996;3:66-70.

[9] Hussain F, Maan MA, Sheikh MA, Nawaz H, Jamil A. Trace elements status in type 2 diabetes. Bangladesh Journal Of Medical Science 2009;8(3)52-6. 
[10] Santa RS, Swati B, Kanika MC, Santasmita P, Aruna B, Gargi S, Soma G. Status of serum magnesium, zinc \& copper in patients suffering from type-2 diabetes mellitus. Journal of drug delivery \& therapeutics 2014;4(1):70-2.

[11] Arpaci D, Tocoglu GA, Ergenc H, Korkmaz S, Ucar A, Tamer A. Associations of serum Magnesium levels with diabetes mellitus and diabetic complications. Hippokratia 2015;19(2):153-7.

[12] American Diabetes Association. Standards of medical care in diabetes- 2017. Diabetes care 2017; 40: S19.

[13] Mostafavi A, Nakhjavani M, Niromanesh SH. Hypomagnesemia and Diabetes Mellitus. IJEM 2003;5(2):111-9.
[14] Mishu AF, Muttalib AM. Serum magnesium and copper in Bangladeshi women with gestational diabetes mellitus. IMC J Med Sci 2017; 11(1):25-8.

[15] AL-Auqbi TFR, Al-Mussawi AMR, Al- Sammraie AMR. Serum Copper, Zinc and $\mathrm{Cu} / \mathrm{Zn}$ ratio in Diabetes. Iraqi J. Comm. Med 2008; 21(1)64-8.

[16] Asemi Z, Karamali M, Jamilian M, Foroozanfard F, Bahmani F, Heidarzadeh $Z$ et al. Magnesium supplementation affects metabolic status and pregnancy outcomes in gestational diabetes: a randomized, doubleblind, placebo- controlled trial. Am J Clin Nutr doi:10.3945/ajen.114.098616. 